\title{
TREATMENT OF NEPHROSIS WITH CONCENTRATED HUMAN SERUM ALBUMIN. II. EFFECTS ON RENAL FUNCTION AND ON EXCRETION OF WATER AND SOME ELECTROLYTES 1, 2, 3
}

\author{
By JOHN A. LUETSCHER, JR., ${ }^{4}$ ALASTAIR D. HALL, ${ }^{5}$ AND VIRGINIA L. KREMER \\ (From the Department of Medicine, The Johns Hopkins University and Hospital, Baltimore)
}

(Submitted for publication, January 25, 1950; accepted, March 20, 1950)

The administration of concentrated human serum albumin to patients with the nephrotic syndrome is followed by an effective diuresis in approximately one-half of the treated cases $(1-4)$. Previous reports $(3,5)$ indicate that the injected albumin is diluted by extracellular fluid to approximately the original level of plasma protein concentration until diuresis occurs. Replacement of the normal total amount of circulating albumin does not regularly ensure a return to normal conditions. The plasma proteins can be concentrated to normal levels only after elimination of most of the edema.

These observations suggest that the inability of the kidneys to excrete normal quantities of sodium and water in nephrosis (6-8) may be a cause, not a consequence, of the edema, and may help to maintain a low plasma protein concentration. In the present study, certain aspects of the renal control of sodium and water excretion are examined, as well as some circulatory and hormonal factors which influence this control.

\section{METHODS}

The 13 patients were adults with the characteristic features of the nephrotic syndrome, without significant hy-

1 A preliminary report of this work was presented at the 39th Annual Meeting of the American Society for Clinical Investigation, Atlantic City, May 5, 1947.

2 This investigation was supported by a research grant from the Division of Research Grants and Fellowships of the National Institutes of Health, U. S. Public Health Service.

${ }^{3}$ The concentrated human serum albumin used in this study was made available in the largest part by the American Red Cross, and in smaller amounts for specific cases by the Sharp and Dohme Company and by the U. S. Navy. Conclusions are those of the authors and do not necessarily reflect the policy of the National Blood Program of the American Red Cross.

4 Present address: Stanford University Hospitals, San Francisco 15, Calif.

5 Present address: Trinity Hospital, Little Rock, Ark. pertension or azotemia. The case numbers below correspond with those in a previous report (3). The patients were studied at bed rest on the metabolism ward, after a control period showed that their weight remained steady or was rising slowly for three to seven days on a constant diet, low in sodium, and on an approximately constant fluid intake. A standard program of treatment (100 cc. of $25 \%$ albumin solution intravenously twice a day) was then instituted for four days, modified occasionally as necessary (3). The study was continued when possible for one to two weeks after the end of treatment.

Sodium and potassium were measured with a flame photometer (9), calcium by Clark and Collip's method (10) and phosphorus by Fiske and Subbarow's method (11). Other methods have been defined previously (3).

\section{RESULTS}

1. Effect on water excretion. The increase of urine volume, shown in Figure 1 , is usually greatest on the first day of treatment, and then falls off slowly during succeeding days. Urine volume returns to the base-line when treatment is discontinued. On the first days of treatment there is a simultaneous increase in the excretion of potassium, non-protein nitrogen, and phosphorus (Figure 1), which are released in amounts considerably larger than those contained in the volume of extracellular fluid eliminated. Increased renal function and diuresis play a role in the temporary elimination of these substances, whose excretion falls below the control level for a few days after treatment is stopped. Definition of intracellular storage of potassium and phosphorus with albumin is so complicated by the falling serum levels and volume changes as to appear unjustified in these patients (3). The urinary excretion of calcium is only slightly increased from its initial very low level.

2. Effect on sodium excretion. The excretion of sodium in the control observations varies from less than $1 \mathrm{~m} . e q$. per day to essentially normal levels. 
When albumin is administered (Figure 2), the average sodium excretion rises progressively during the first three days of treatment, falling off on the fourth day and then decreasing to below the control levels in the next six days. While the excretion of sodium in the urine thus lags behind the excretion of water on the first days of treatment, this relatively hypotonic diuresis is reflected in a rising serum sodium concentration (Figure 3 ). A similar delay in sodium and chloride excretion has been noted in the first days of a spontaneous diuresis of nephrosis $(12,13)$, and in other patients treated with albumin (13-15).

The flexibility of the renal regulation of sodium is emphasized by the factor of almost 1,000 between the lowest and the highest levels of daily sodium excretion, in contrast to the much smaller fluctuations in the excretion of water and other urinary components.

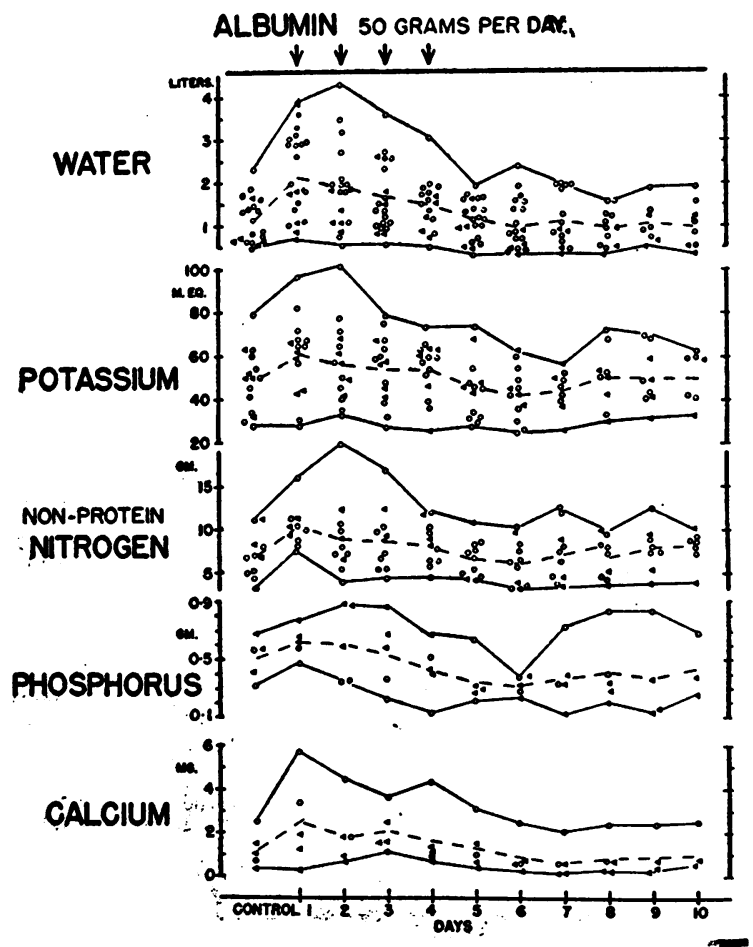

Fig. 1. The Effect of Injections of Albumin on the Excretion of Water and of Some Solutes

Twenty courses of treatment in 13 patients are included. The outer lines indicate the range, and the inner, broken line shows the average of the measurements. Open circles represent cases treated with salt-poor albumin, while solid triangles show those treated with albumin of high sodium content. Note the general parallelism between the upper four curves.

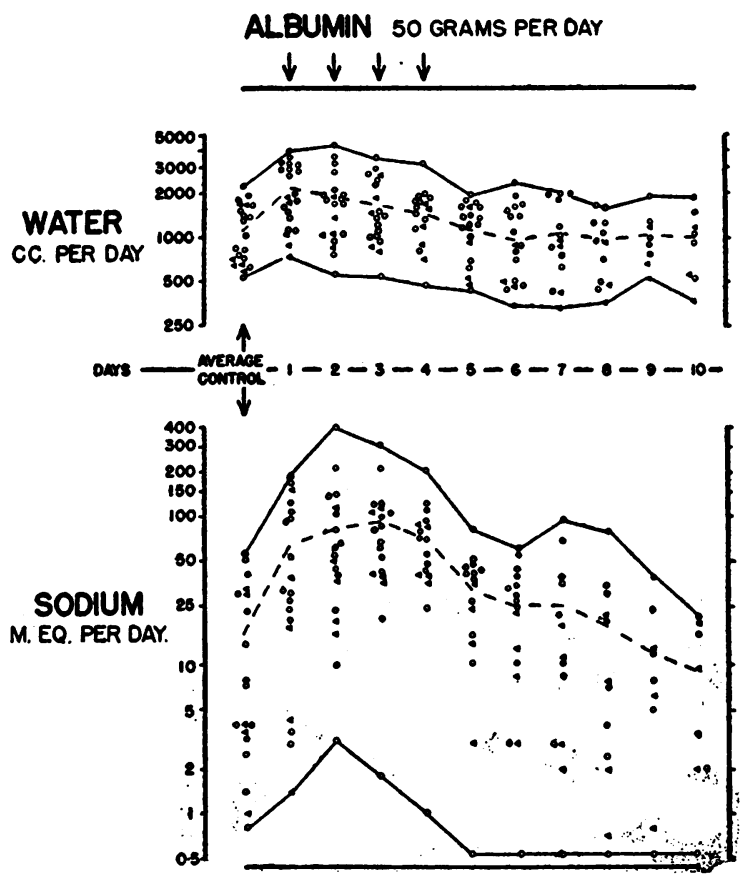

Fig. 2. The Effect of Injections of Albumin on the Excretion of Sodrum AND WATER

Twenty courses of treatment in 13 patients are represented, with the lines indicating range and average. Open circles are patients on salt-poor albumin, solid triangles are those on high-sodium albumin. The results are plotted on a semilogarithmic scale, which shows the greater variability of sodium excretion. Note the lag in maximum excretion of sodium after the peak of water excretion.

3. Relation between sodium excretion, water excretion and body weight. Rapid changes in body weight, observed in these patients on a constant diet at rest in a cool environment, can be correlated with water intake and urinary volume (Figure 3 ). While the effect of sodium balance is not as quickly manifest, the retention of sodium over a period of days is cumulative and can prevent further diuresis. Five examples are presented in Figure 3. An initial diuresis can occur even though the patient is in positive sodium balance. It seems probable that the temporary excretion of water without sodium is limited by the rising serum sodium concentration, and that subsequent excretion of extracellular water can proceed only if a comparable amount of sodium is eliminated.

Case 6 (Figure 3) illustrates the course of events in a patient who had a sustained diuresis 


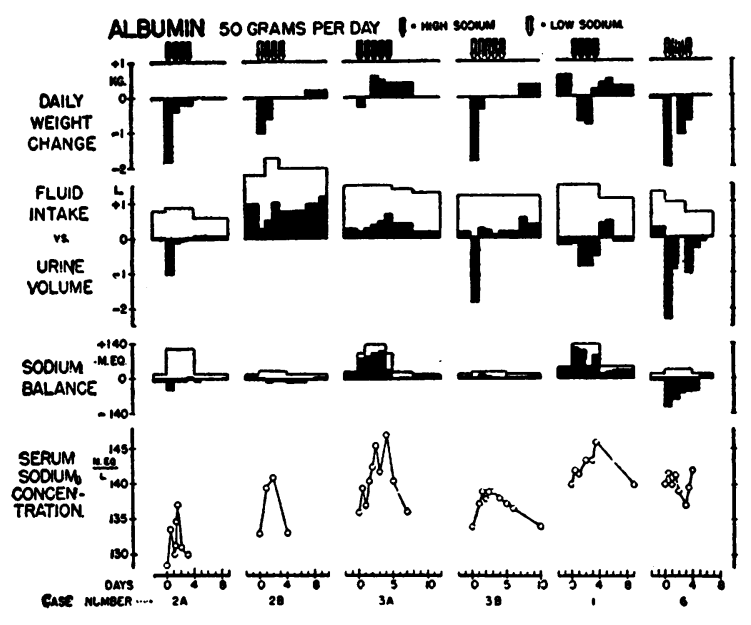

Fig. 3. Effects of Injection of Albumin of Varying Sodium Content on Sodium and Water Exchange and on the Concentration of Sodium in Serum

Intake of water and sodium is plotted above the zero line, and output is subtracted. The resultant balance is indicated by the solid blocks, which show gain of weight, water, or sodium when they are above the zero (balance) line. Solid blocks below the zero line show loss of the component involved. Note the general parallelism between weight and water exchange. Sodium excretion is usually smaller in amount, with a corresponding rise in serum sodium concentration. Only temporary elimination of water occurs if sodium is retained.

with nearly complete relief of his edema. The initial loss of water in the urine was accompanied by an increased excretion of sodium, which was somewhat less impressive than the water loss on the first day of treatment. Sodium excretion was then maintained after water excretion diminished, and continued for a day after treatment was stopped. The serum sodium concentration did not show a large or sustained increase in this patient.

4. Administration of sodium plus albumin. Some of the first concentrated human serum albumin prepared by the American Red Cross contained a high concentration of sodium salts (approximately $380 \mathrm{~m}$. eq./L.), but subsequent lots have been issued with a much lower sodium content (approximately $130 \mathrm{~m} . e q . / \mathrm{L}$.; some of the albumin used in this study contained as little as 80 m.eq./L.). The pattern of sodium excretion of the five cases receiving the high-sodium albumin differed in no significant way from the rest of the group, who received salt-poor albumin (Figure 2).

A comparison of the effects of albumin, hyper- tonic or hypotonic in sodium, was made in three patients, each of whom received albumin on two different occasions. Cases 1 and 3 seemed to do a little better on salt-poor albumin, but no striking benefit was observed (3). The urinary sodium was slightly higher when high-sodium albumin was given than when the same patient was given salt-poor albumin. When the increased excretion of sodium was compared with the extra load, however, the diuretic effect of the highsodium albumin was outweighed in two of the three cases by the retention of sodium (cases 1 and 3 , Figure 3 ). In case 2 , there was little to choose between the two types of albumin, for the patient stayed essentially in sodium equilibrium

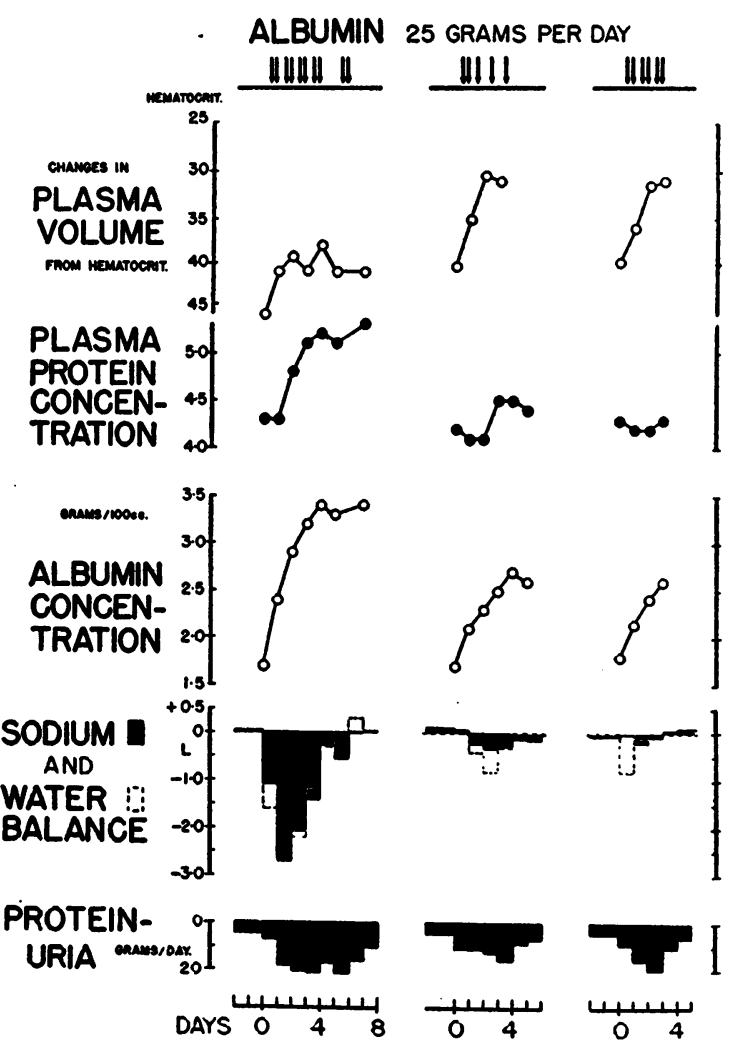

Fig. 4. Different Results of Three Courses of Treatment in the Same Patient

Compare especially the first three days of the first and third courses, when circulating albumin was comparatively increased. When diuresis of water and sodium occurred (course I), plasma protein and albumin were concentrated in a smaller plasma volume. When sodium was not excreted (course III), only a little water was lost, and the injected albumin was diluted in a large increase of plasma volume. 
during both courses of treatment, while diuresis was transient and insignificant in comparison with the large collection of edema. The response of case 2 may have been influenced by the very low serum sodium concentration preceding the administration of the high-sodium albumin.

No conclusions concerning the relative merits of various sodium concentrations of albumin can be drawn from such a brief study. In general, any added load of sodium is a liability in the nephrotic syndrome and should be avoided unless the serum sodium concentration is significantly reduced.

5. The effect of sodium and water excretion on hypoproteinemia cannot be neglected. Figure 4 illustrates the response of a patient (case 11) to three courses of treatment with salt-poor albumin. On the first occasion, there was a prompt and complete diuresis, beginning on the first day of treatment. At the end of three days, the plasma protein and albumin concentrations were at nearly normal levels. It is seen that the plasma albumin concentration rose steadily during this period, doubtless contributing to the continuing "mobilization" of edema fluid. The plasma protein concentration stayed constant for the first day, presumably because of dilution of the injected albumin with edema fluid, as suggested by the falling hematocrit. After the second day, when diuresis was at its height, the plasma protein concentration rose sharply and continued to increase until diuresis ceased.

The second course of treatment consisted of fewer injections, but the third course was identical with the first three days of the first course of injections. The results of the third course were quite different, as only a small and transient diuresis occurred and very little sodium was eliminated. The plasma protein concentration was unchanged. The plasma albumin concentration rose somewhat less than on the first occasion, while the dilution of the blood was somewhat greater, to judge by the hematocrit. Proteinuria was, if anything, slightly less during the third course than during the comparable period of the first course of treatment.

It seems probable that excretion of sodium and water is necessary to concentrate the plasma proteins. The injection of albumin "mobilizes" fluid, but if the kidneys fail to excrete the excess of fluid, further injections of albumin serve only to dilute the blood. The failure of renal sodium excretion, by preventing diuresis, can perpetuate the hypoproteinemia and edema even though the deficit of circulating albumin is made up by injection of concentrated albumin (3).

6. Notes on some possible causes of failure to excrete sodium and water. In attempting to treat the severe form of nephrosis, which is resistant to albumin therapy, it would be helpful if we could define more exactly the factors which control the renal excretion of sodium and water. Some observations and certain published data may be relevant.

A. Protein deficiency may impair the renal excretion of sodium and water to a limited degree. We have found $(13,16)$ in dogs that chronic protein depletion, produced by diet with or without repeated plasmapheresis, not only reduces the glomerular filtration rate but also reduces the ability of the dog to excrete sodium under the stress of large, intravenous injections. This reduction is not large enough, however, to cause sodium retention when the intake of sodium is low. These data correspond with the observations in patients with hypoproteinemia not associated with renal disease, who frequently lose their edema at bed rest on a low-sodium diet (17), and who respond to albumin therapy with diuresis (18).

B. Hypoproteinemia may allow the escape of fluid through the capillaries, but hypoproteinemia does not prevent diuresis in patients, who may lose all visible edema while the plasma protein and albumin levels remain far below normal. Severe hypoproteinemia produced by acute plasmapheresis in dogs does not reduce the renal ability to excrete sodium $(13,16)$.

C. Reduction in blood volume has been implicated by Borst (19) and Peters (20) as a possible cause of renal sodium and water retention. This is a very attractive idea, and may well account for the situation in the milder form of nephrosis. Even though our measurements of plasma volume in patients with nephrosis show only moderately subnormal levels, the total circulating albumin and globulin are at such low levels that the circulation could scarcely be maintained if the protein were not diluted to a low concentration, thus allowing the maintenance of an adequate plasma volume. It is possible that the diuretic effect of albumin is related to the expansion of plasma volume, since 


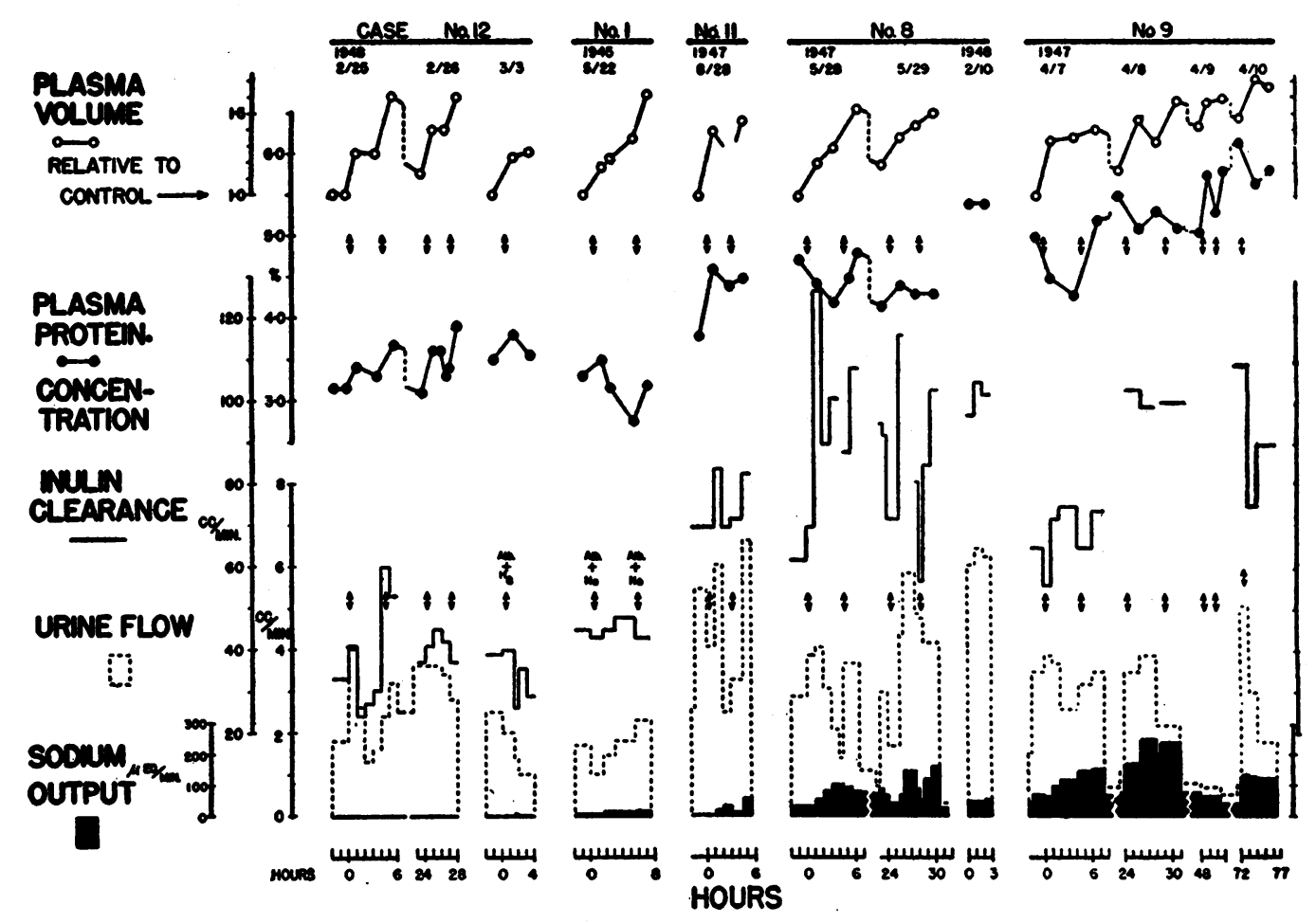

Fig. 5. Effect of Injections of Albumin on Several Factors Affecting the Excretion of Sodium

Small arrows indicate injections of salt-poor albumin. $A l b .+H g$ shows the simultaneous injection of salt-poor albumin and mercurophylline. $A l b .+\mathrm{Na}$ marks the injection of albumin of highsodium content. Plasma volume is plotted in relation to the pre-treatment volume taken as unity. The excretion of water and of sodium are plotted on a scale ten times greater than that indicating the clearance of inulin. Note that although increases in plasma volume and in glomerular filtration rate favor the excretion of sodium, neither appears to be the determining factor. Urine flow appears irrelevant.

the increased output of sodium appears at a time when maximum dilution of injected albumin occurs (Figure 5). Further expansion of plasma volume may not increase sodium excretion to a still higher level. Moreover, in severe forms of nephrosis, a very large increase of plasma volume does not necessarily lead to diuresis.

Anemia may play a role, inasmuch as we have occasionally seen some diuresis or greater responsiveness to albumin after red cell infusions.

D. Plasma sodium concentration is frequently reduced in severe nephrosis, but it has already been pointed out that raising this concentration to normal or higher is not regularly followed by increased sodium excretion (Figure 3 ).

E. Glomerular filtration rate may be supranormal in children, but most adults with the nephrotic syndrome show some depression of inulin clearance. Since many patients with advanced renal disease have a grossly reduced filtration rate without edema, it is difficult to evaluate this finding. Nevertheless, in our patients with the nephrotic syndrome, those with the lowest filtration rates have the lowest sodium output, the poorest diuretic response to albumin, and in one case, a negligible increase in sodium output after a mercurial diuretic (Figure 5).

The rates of glomerular filtration and of sodium excretion are regularly increased after treatment with albumin (Figure 5). Although the level is too low to show in the graph of case 12 , there is a regular, though infinitesimal, increase in the small excretion of sodium (from a minimum of 0.04 micro-equivalent per minute to a maximum of 1.1 micro-equivalents per minute).

The increases in glomerular filtration rate and 
in sodium excretion do not necessarily follow at the same time after albumin is injected. Moreover, the changes in glomerular filtration and in sodium output are not proportional or parallel. No critical level of filtration rate is seen in any patient, above which sodium is excreted or below which sodium is not excreted. Although the scale of sodium excretion is enlarged by a factor of 10 as compared with the filtration rate in Figure 5, the variations in sodium excretion are small as compared with the large variations in filtration rate. It is apparent that although changes in glomerular filtration rate influence the sodium output, the tubule has the last word in determining sodium excretion.

F. Sodium reabsorption in the renal tubules is nearly complete in the edematous phase of nephrosis. The percentage of filtered sodium appearing in the urine varies from $0.001 \%$ to $0.5 \%$ (average $0.18 \%$ ) before treatment in the cases in Figure 5. Whether the sodium retention is due to the subnormal glomerular filtration rate or to tubular activity is not known, but the results of treatment with albumin suggest that both factors may be involved. When the injections of albumin increase the glomerular filtration rate, the absolute increase in urinary sodium is much smaller than the increased tubular load of sodium. The excretion of sodium may increase, however, without a rise in the filtration rate. Urinary sodium is excreted at a higher than control level when the filtration rate has returned to the control level after a temporary increase (Figure 5).

These observations suggest that renal tubular activity in the reabsorption of sodium is increased over and above the apparent changes due to a decreased load. The demonstration by Deming and and Luetscher (21) of an increased level of sodium-retaining steroids in the urine of patients in the edematous phase of nephrosis offers a partial explanation. It is of interest that the level of sodium-retaining steroids fell in the patient observed after the administration of albumin.

Increased intra-abdominal pressure may reduce the excretion of sodium $(22,23)$. We have noted that a large, tense collection of ascitic fluid appears to interfere with diuresis when albumin is given, while a better result may follow paracentesis and another course of albumin.
G. Water reabsorption in the renal tubules is increased in the severe forms of nephrosis. The small, highly concentrated urine contrasts strikingly with the edema and with the hypotonicity of the body fluids. In such cases, increased antidiuretic activity, probably hormonal (24), can usually be suppressed by albumin injections with resultant water release (Figures 1-3).

Albumin has sometimes been called an osmotic diuretic, but our observations do not confirm this notion. Although much albumin may appear in the urine, its molecular weight is so high that it has little effect on the osmolar concentration of urine (measured by depression of freezing point), which usually falls on the days of maximal diuresis. Moreover, neither in spontaneous diuresis nor after albumin treatment is there any positive correlation between proteinuria and the volume or sodium content of the urine. On the contrary, the cases with the heaviest proteinuria generally show the least diuresis (3), and diuresis usually occurs well before the development of maximum proteinuria. In general, the response after albumin is quite different from the effects of urea or mannitol, which we have used as osmotic diuretics in a few patients.

\section{DISCUSSION}

The importance of sodium and water in the maintenance both of the internal environment and of the circulation requires the accurate regulation of sodium concentration, as well as of the volume, of the plasma and interstitial fluid. The complexity of this task and the adaptations encountered in disease strongly suggest that no simple mechanical arrangement at the capillary or kidney alone could be trusted to accomplish all these ends.

The original concept of Starling (25) of the balance of hydrostatic and osmotic forces in the capillaries remains as sound as ever, but explanations of edema which rest on clinical measurements of only a part of the several forces involved are oversimplified. Moreover, such explanations fail to take into account the participation of other organs. If the kidneys retain sodium and water until the outward passage of fluid through the capillaries meets increasing resistance, the plasma itself may be diluted. The new equilibrium acts as though it were buffered at a lower effective hy- 
drostatic pressure and a lower colloid osmotic pressure, so that added albumin is simply diluted (3.) We can only guess whether this is due to a lower intracapillary pressure or to a higher tissue pressure or to a combination of the two.

Renal retention of salt and water presumably plays an important part in the maintenance of the circulation in the face of a severe deficiency of plasma proteins. If it were possible to concentrate the plasma proteins of the severe nephrotic to a normal colloid osmotic pressure without addition of protein, the plasma volume would be too small to sustain life. Thus, although hydremia has been eliminated as the first cause of hypoproteinemia in nephrosis (26), dilution of the depleted circulating protein to sustain the plasma volume is often a life-saving compensation.

The mechanism of this compensatory hydremia and incidentally of the edema appears to be complex, but the most important factors seem to be a decreased glomerular filtration rate and an increased reabsorption of salt and water by the renal tubules. The lowest filtration rates were seen in the most intractable forms of edema, which failed to respond to albumin or even to mercury. Such severe reductions of filtration rate could scarcely be attributed to protein depletion or to the reduced blood volume without clinical circulatory inadequacy. We have not found comparable reductions in filtration rate in studies on patients with hypoproteinemia without renal disease. Disease of the glomeruli seems a more likely explanation in the severe forms of the nephrotic syndrome. In the milder cases, albumin effectively increases the filtration rate, but such increases can not be systematically correlated with the sodium output.

The handling of sodium and water by the renal tubules seems to be the more important factor. Since these tubular functions are controlled by hormonal stimuli, it is not surprising that Robinson and Farr (24) noted increased antidiuretic activity and that Deming and Luetscher (21) have noted high levels of sodium-retaining steroids in a few patients with nephrosis and cardiac failure.

The greater difficulty with which sodium is eliminated has focused clinical interest more on sodium than on water retention as a cause of edema in nephrosis. Nevertheless, the change in water excretion generally precedes the change in sodium excretion, not only after albumin treatment but also during spontaneous diuresis or recurrence of edema in nephrosis (12-15). It would appear that the antidiuretic stimulus is more sensitive to the changes in plasma volume which accompany the changes in hydration or the addition of protein to the plasma. Antidiuretic hormone may be evoked either by an insufficient circulation or by hypertonicity of the body fluids (27, 28). The water diuresis after albumin treatment is apparently limited by the rising serum sodium concentration, if the kidneys fail to release sodium.

The serum sodium concentration is usually slightly below normal in the patient with nephrosis (29), presumably because the antidiuretic effect outweighs the sodium retention. When water diuresis is induced by albumin injections, the serum sodium concentration rises. Peters (30), on the basis of the experiments of Orloff, Welt, and Stowe (15), suggests that the stimulus to sodium excretion is the rising total osmotic activity of the body fluids, following the increase in serum sodium concentration. Our results show, however, that significant increases in sodium excretion do not necessarily follow even when the serum sodium concentration is increased above normal levels. A similar retention of sodium chloride with high serum levels occurs after gastro-intestinal hemorrhage (19), but this must be distinguished from high serum sodium and chloride levels due to acute loss of water without sodium in diabetes insipidus (20) and after renal injury (31), when the renal mechanism is quite different.

This failure to excrete sodium, even when the concentration in the body fluids is above normal, might be attributed to a reduced glomerular filtration rate or to excessive sodium-retaining activity of the renal tubules, probably under adrenal control. The circumstances which lead to decreased glomerular filtration rate and to adrenocortical sodium-retaining activity are similar. Both mechanisms could be set in motion by the fall in plasma volume in nephrosis, just as they are both active in severe congestive heart failure $(20,32)$. It would appear that the regulation of sodium and water excretion can be adequately explained only by direct measurements which include specific renal and hormonal functions. 


\section{SUMMARY}

1. The administration of concentrated human serum albumin in dosage of 50 grams per day for three to six days results in a diuresis which varies considerably in different patients and in the same patient on different occasions. Five of 13 patients lost all edema.

2. A diuresis of water occurs quite regularly on the first day of treatment and is accompanied by a corresponding loss of weight. On subsequent days, the excretion of water usually falls off slowly.

3. The excretion of potassium, phosphorus, nitrogen, and calcium generally follows the urine volume.

4. Sodium excretion is highly variable. No appreciable increase may occur. In other cases, sodium appears in the urine in increasing amounts, reaching a peak on the second to fourth day.

5. As a result of the earlier excretion of water, the serum sodium concentration rises temporarily, but sodium excretion is not determined by the level of the serum sodium in the patients studied.

6. If sodium excretion does not follow the initial water diuresis, no further elimination of water occurs.

7. In the patients studied, severe reduction in glomerular filtration rate is associated with a very low sodium output and with intractable edema.

8. Increased tubular reabsorption of water and sodium under hormonal control is probably an equally important factor in the causation of edema.

9. After injection of albumin the increases in glomerular filtration rate and in sodium excretion are not necessarily simultaneous or proportional. Maximum filtration rate and sodium excretion usually follow one-half to two hours after the end of an injection, at a time when the plasma volume has been much increased and when the colloid osmotic pressure of plasma is falling.

10. Possible interactions of these factors are discussed.

\section{CONCLUSIONS}

The sequence of events after injection of albumin appears to be: (1) Increased colloid osmotic pressure of plasma. (2) Dilution of the plasma with extracellular fluid to nearly the original plasma protein concentration. (3) Increased glomerular filtration rate. (4) Increased excretion of water. (5) Increase in serum sodium concentration.

At this juncture, two possibilities exist: $(6 a)$ If glomerular filtration is adequate, the renal tubules may reject some sodium. The amount of sodium appearing in the urine determines the subsequent diuresis and the increase in concentration of the plasma proteins. Or ( $6 b)$ No sodium is excreted, due to renal or adrenal factors. In this case, the increased concentration of serum sodium apparently stops the water diuresis, and further treatment is ineffectual in relieving the edema or in significantly increasing the plasma protein concentration.

\section{BIBLIOGRAPHY}

1. Janeway, C. A., Gibson, S. T., Woodruff, L. M., Heyl, J. T., Bailey, O. T., and Newhouser, L. R., Concentrated human serum albumin: albumin in treatment of shock; safety of albumin; albumin in treatment of hypoproteinemia. J. Clin. Invest., 1944, 23, 465.

2. Thorn, G. W., Armstrong, S. H., Jr., Davenport, V. D., Woodruff, L. M., and Tyler, F. H., Chemical, clinical, and immunological studies on products of human plasma fractionation. XXX. Use of saltpoor concentrated human serum albumin solution in treatment of chronic Bright's disease. J. Clin. Invest., 1945, 24, 802.

3. Luetscher, J. A., Jr., Hall, A. D., and Kremer, V. L., Treatment of nephrosis with concentrated human serum albumin. I. Effects on the proteins of body fluids. J. Clin. Invest., 1949, 28, 700.

4. Seegal, D., and Wertheim, A. R., Recent advances in our knowledge concerning the nephrotic syndrome. Bull. N. Y. Acad. M., 1949, 25, 605.

5. Luetscher, J. A., Jr., The effect of a single injection of concentrated human serum albumin on circulating proteins and proteinuria in nephrosis. J. Clin. Invest., 1944, 23, 365.

6. Magnus-Levy, A., Natrium- und Kaliumsalze bei Wassersucht. Ztschr. f. klin. Med., 1928, 107, 659.

7. Blum, L., and Van Caulaert, C., Le Role du Sel dans les Néphrites: Etude Clinique, Physiopathologique, et Thérapeutique. Masson et Cie., Paris, 1931.

8. Loeb, R. F., Atchley, D. W., Richards, D. W., Jr., Benedict, E. M., and Driscoll, M. E., On the mechanism of nephrotic edema. J. Clin. Invest., 1932, 11, 621.

9. Berry, J. W., Chappell, D. G., and Barnes, R. B., An improved method of flame photometry. Indust. Eng. Chem. (Analyt. Ed.), 1946, 18, 19.

10. Clark, E. P., and Collip, J. B., A study of the Tisdall method for the determination of blood serum cal- 
cium with a suggested modification. J. Biol. Chem., $1925,63,461$.

11. Fiske, C. H., and Subbarow, Y., The colorimetric determination of phosphorus. J. Biol. Chem., 1925, 66, 375.

12. Rytand, D. A., Chronological separation of water and chloride diuresis in nephrotic syndrome. Am. J. Med., 1948, 4, 624.

13. Hall, A. D., and Luetscher, J. A., Jr., Renal disease. New England J. M., 1948, 239, 621.

14. Janeway, C. A., Moll, G. H., Armstrong, S. H., Jr., Wallace, W. M., Hallman, N., and Barness, L. A., Diuresis in children with nephrosis. Comparison of response to injection of normal human serum albumin and to infection, particularly measles. Tr. A. Am. Physicians, 1948, 61, 108.

15. Orloff, J., Welt, L. G., and Stowe, L., The effects of salt-poor albumin on the excretion of water and electrolytes in edematous patients. J. Clin. Invest., 1949, 28, 802.

16. Luetscher, J. A., Jr., and Hall, A. D., The relationship between the plasma protein level, the renal excretion of sodium, and edema. J. Clin. Invest., 1948, 27, 548.

17. Denz, F. A., Hunger oedema. Quart. J. Med., 1947, $16,1$.

18. Armstrong, S. H., Jr., Mechanisms of action of serum albumin therapy in internal medicine. Am. J. Med., 1948, 4, 390.

19. Borst, J. G. G., The cause of hyperchloremia and hyperazotemia in patients with recurrent massive hemorrhage from peptic ulcer. Acta med. Scandinav., 1938, 97, 68.

20. Peters, J. P., The role of sodium in the production of edema. N. England J. M., 1948, 239, 353.

21. Deming, Q. B., and Luetscher, J. A., Jr., Bio-assay of desoxycorticosterone-like substances in urine. Proc. Soc. Exper. Biol. \& Med., 1950, 73, 171.
22. Thorington, J. M., and Schmidt, C. F., A study of urinary output and blood-pressure changes resulting in experimental ascites. Am. J. M. Sc., 1923, $165,880$.

23. Bradley, S. E., Mudge, G. H., Blake, W. D., and Alphonse, P., The effect of intra-abdominal pressure upon renal excretion of water, sodium and potassium in normal human subjects and in patients with diabetes insipidus. J. Clin. Invest., 1949, 28, 772.

24. Robinson, F. H., Jr., and Farr, L. E., The relation between clinical edema and the excretion of an antidiuretic substance in the urine. Ann. Int. Med., 1940, 14, 42.

25. Starling, E. H., The Fluids of the Body. The Herter Lectures (1908). W. T. Keener \& Co., Chicago, 1909.

26. Linder, G. C., Lundsgaard, C., Van Slyke, D. D., and Stillman, E., Changes in the volume of plasma and absolute amount of plasma proteins in nephritis. J. Exper. Med., 1924, 39, 921.

27. Verney, E. B., Absorption and excretion of water; the antidiuretic hormone. Lancet, 1946, 2, 739 and 781.

28. Brun, C., Knudsen, E. O. E., and Raaschou, F., Kidney function and circulatory collapse; postsyncopal oliguria. J. Clin. Invest., 1946, 25, 568.

29. Peters, J. P., Wakeman, A. M., Eisenman, A. J., and Lee, C., Total acid-base equilibrium of plasma in health and disease. XII. A study of renal edema. J. Clin. Invest., 1929, 6, 577.

30. Peters, J. P., The significance of serum sodium. McGill M. J., 1949, 18, 130.

31. Luetscher, J. A., Jr., and Blackman, S. S., Jr., Severe injury to kidneys and brain following sulfathiazole administration; high serum sodium and chloride levels and persistent cerebral damage. Ann. Int. Med., 1943, 18, 741.

32. Merrill, A. J., Mechanisms of salt and water retention in heart failure. Am. J. Med., 1949, 6, 357. 